\title{
La imagen del poder: la representación militar en la década de los setenta ${ }^{1}$
}

\author{
https://doi.org/10.21830/9789585380219.06
}

\author{
Andrea Katherinne Diaz Cante ${ }^{2}$ \\ Escuela Militar de Cadetes "General José María Córdova”
}

\begin{abstract}
Resumen. El presente capítulo presenta un estudio sociológico e histórico de la Escuela Militar de Cadetes “General José María Córdova” en la década de los setenta. Con este propósito, se hace un análisis del archivo fotográfico de la institución a partir de distintas categorías teóricas de Pierre Bourdieu, Peter Burke y Roland Barthes. La investigación, producto de una tesis de maestría, evidencia la jerarquía institucional, los distintivos, las condecoraciones, los uniformes y los rangos como bienes capitales culturales y simbólicos que los cadetes incorporan en su proceso de formación y educación militar. Se concluye que los cadetes y alféreces adquieren como propio un habitus que legitima el campo militar y, a la vez, les permite ser parte de este para poder ascender y posicionarse.
\end{abstract}

Palabras clave: educación; formación militar; historia militar; imagen histórica; representación militar.

\section{Introducción}

El presente texto describe y analiza la materialización conceptual de la teoría sociológica e histórica en la Escuela Militar de Cadetes "General José María Córdova” (EsMic), con el fin de comprender cómo se construye la repre-

1 Este capítulo de libro presenta los principales resultados de la tesis de maestría Representación militar de la Escuela Militar de Cadetes "General José María Córdova" en la década de los setenta del siglo XX, de la Maestría en Historia Militar de la Esmic, Bogotá, D. C., Colombia. Los puntos de vista y los resultados presentados en este capítulo pertenecen a la autora y no reflejan necesariamente los de las instituciones participantes.

2 Magíster en Historia Militar de la Escuela Militar de Cadetes “General José María Córdova”. Licenciada en Ciencias Sociales de la Universidad Distrital Francisco José de Caldas. Coordinadora de Investigación del Departamento de Historia Militar de la Facultad de Ciencias Militares de la Esmic, Bogotá, D. C., Colombia. Orcid: https://orcid.org/0000-0003-0347-6146 - Contacto: andrea.diaz@ esmic.edu.co 
sentación militar en la institución a través de sus procesos de formación. Al respecto se debe resaltar que si bien las ciencias sociales y el ámbito militar han tenido a menudo una compleja relación, aun así han llegado a tener afinidad en la realización de estudios concernientes a la caracterización de los agentes armados, sus relaciones con el Estado, las implicaciones en el avance armamentístico o el papel que han tenido en la historia del país; precisamente, en el mismo nivel de interpretación se encuentran los estudios históricos. La indagación en torno a los militares como objeto de estudio no ha sido abordada desde la sociología o la etnografía, no existen estudios sociológicos históricos de la conformación militar o de sus estructuras, y lo mismo se podría decir en el campo etnográfico.

En este trabajo se estudia el ámbito militar desde las ciencias sociales con el fin de acercarse a la comprensión y conformación (sociológica) del campo militar ${ }^{3}$, lo que permite identificar los habitus que se reproducen entre los militares, para lo cual se recurre a material visual de mediados del siglo XX, específicamente de la década del setenta en Colombia. Desde esta perspectiva, es posible plantear las siguientes preguntas: ¿Estos habitus son propios de esa época o son heredados? ¿Cómo han configurado los militares las actitudes de lo militar? ¿Cómo son sus bienes y capitales simbólicos y cómo se hacen evidentes en la fotografía? ¿Cómo se configura la jerarquía de los agentes militares dentro de dicho campo sociológico? ¿Qué elementos la distinguen?

A partir de lo anterior, se decidió hacer un estudio desde la sociología histórica en el ámbito militar a partir de la fotografía, ya que hace posible tener un acercamiento distinto a la comprensión de la representación militar o del ser militar, a la vez que reconocer la configuración de una imagen de poder. Desde esta perspectiva, se entiende que la fotografía es una "herramienta de exploración de la sociedad” (Becker, 1974, p. 6) y que, por lo tanto, el análisis de un archivo fotográfico como fuente primaria de indagación permite explorar y explicar cómo se configura la identidad militar, para lo cual se recurre también a las propuestas teóricas de Pierre Bourdieu (1997), Peter Burke y Roland Barthes $(1986,1990)$. De esta manera, se planteó un estudio sociológico histó-

3 Se entiende campo como un lugar, ámbito u ambiente cuya atmósfera permea a todos los agentes o personas que lo configuran. En este caso, el campo es la Escuela Militar, de ahí el campo militar. 
rico de la imagen que permitió responder la siguiente pregunta: ¿Cómo se construye y comprende la representación de los militares de la Escuela Militar de Cadetes “General José María Córdova” en la década de los setenta del siglo XX en Colombia?

Específicamente, se plantearon los siguientes objetivos de investigación: (1) establecer la representación militar a través de la imagen y cómo esta responde en sus diferentes dimensiones al campo que la configura; (2) analizar la estructura sociológica del campo militar en la década de los setenta desde los conceptos propuestos por los teóricos, y (3) realizar un esquema en torno al campo militar que dé cuenta de las jerarquías y los agentes que allí interactúan, a la vez que de cómo se relacionan con los diferentes capitales y bienes propios del campo.

\section{Métodos}

Esta investigación empleó una metodología con un enfoque epistemológico que permitió dilucidar los caminos entre la teoría y la relación con la práctica investigativa. Así, la sociología histórica de la imagen fue el punto de partida para realizar la pesquisa, de tal manera que aportó los insumos para la lectura de la imagen, a la vez que permitió analizar y descifrar una construcción o acercamiento de lo que es y se muestra en las fotografías históricas de la EsMic.

Además, este trabajo usó el método investigativo de la fenomenología, el cual exalta la relación entre el investigador y la fuente de la investigación para evidenciar la interpretación del acto investigativo. De esta forma, la investigadora pudo sentir y entender lo que transmiten los archivos fotográficos de la Esmic, en los cuales la materialización del concepto se hace realidad en su campo. Específicamente, la técnica de investigación consistió en dos procedimientos: por una parte, la recolección de datos, sobre todo del registro fotográfico de la década de los setenta, recurso que permitió tener un acercamiento a las categorías y extraer de ellas información. De otra parte, se hizo una recolección de información de carácter documental y teórica, que se apoyó en la recopilación de antecedentes a través de documentos teóricos y gráficos (fotografías 
y videos) de diversos autores. Además, se consultaron fuentes primarias: los archivos y manuales del Ejército Nacional, especialmente los que impactan a la EsMic, así como entrevistas a quienes fueron cadetes de la institución durante el período histórico estudiado, que corresponde de 1970 a 1979.

\section{La construcción de la representación militar}

Este producto de investigación analiza específicamente dos fotografías del archivo consultado, las cuales evidencian la materialización de los conceptos sociológicos planteados.

La primera fotografía (figura 1) destaca la presencia del presidente Alfonso López Michelsen (gobierno de 1974 a 1978) en una ceremonia de graduación en la Esmic. Acompañando al presidente está el Brigadier General Bernardo Lema Henao, director de la Escuela, quien hace entrega del diploma como subtenientes de la República de Colombia. Para analizar esta fotografía se debe tener en cuenta que la Constitución actual de Colombia — así como las anteriores - establece que el presidente es el comandante en jefe de la Fuerza Pública de Colombia, de manera que la fotografía resalta la injerencia del mandatario como representante del campo político sobre el campo de las Fuerzas Militares. Esto demuestra el interés del gobierno por mantener y controlar el ejercicio de la violencia legítima del Estado, es decir, de las Fuerzas Militares, pues son las encargadas de ejercer y mantener el orden social de los otros campos, aun cuando estas obedecen al campo político. De allí el significado de que la ceremonia de ascenso de los militares, después de que han concluido su carrera y se les reconoce como agentes del campo, sea la única en la que está presente el jefe de Estado.

El hecho de que estas personalidades ejerzan intereses externos del campo que están presentes en él evidencia que este campo está ligado a lo que demande el Ministerio de Defensa y el Ministerio de Educación, y, a su vez, estos al presidente de la República o al gobierno de turno. Específicamente, la entrega del diploma se convierte en un estado objetivado, a lo que Bourdieu (1997) se refiere como los bienes culturales hechos materiales. En este sentido, el diploma y el sable que obtiene el militar desde que se convierte en alférez 


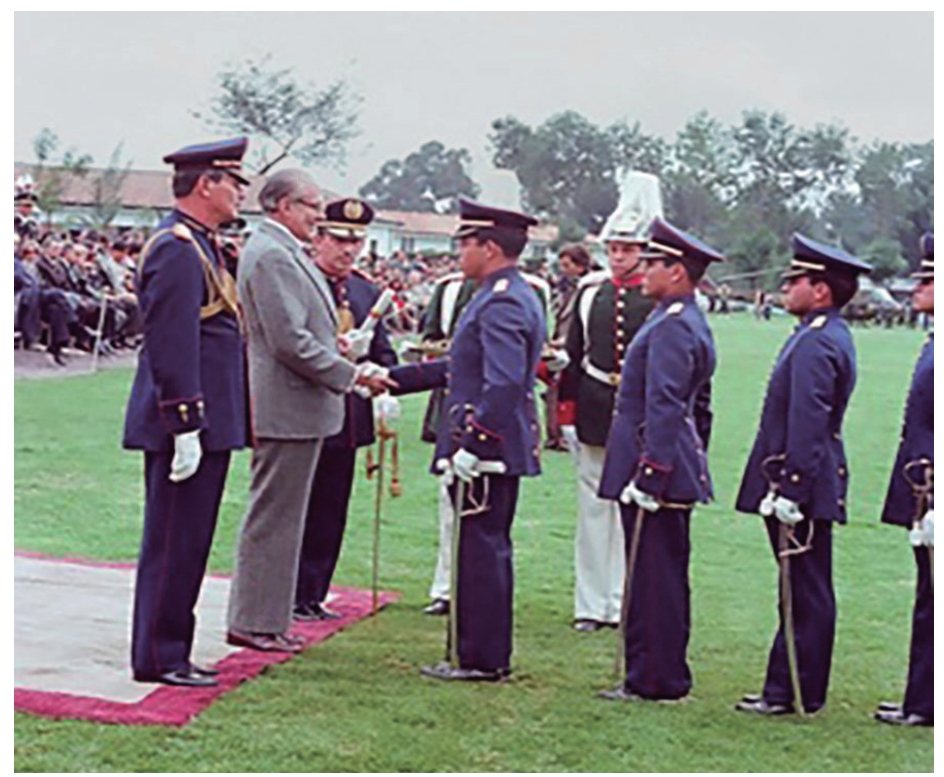

Figura 1. Ascenso a subtenientes en la Esmic (1977). El presidente de la República, Alfonso López Michelsen, y el Brigadier General Bernardo Lema Henao, director de la Escuela, entregan los diplomas a los recién ascendidos.

Fuente: Álvaro Díaz. Archivo fotográfico personal, Bogotá, D. C., Colombia.

son los bienes y capitales simbólicos que le permiten, ya del todo, ser reconocido como oficial y diferenciarse del cadete. En otras palabras, se convierten en elementos de distinción dentro de todos los agentes que componen el campo militar, pues en esta ceremonia también obtiene el grado de subteniente y su primera insignia, que es la estrella.

Este acto ceremonial, donde estaban presentes todos los uniformados que ascendían, era realizado en orden: iniciaba por el primer puesto, a quien se le entregaba el título y el reconocimiento a sus méritos, y luego seguían los demás de acuerdo con el puesto que hubieran obtenido en sus procesos de formación, tanto por sus estudios académicos como por su instrucción militar.

Actualmente, esto solo se realiza con los diez primeros puestos, quienes reciben el saludo del presidente de turno y de la cúpula militar. Esto muestra que quienes alcanzan esos diez primeros puestos ya han configurado unos bienes y capitales simbólicos, que les crean el prestigio social necesario para ser destacados dentro del campo. De esta manera, logran distinguirse de los 
demás graduandos por sus calificaciones y las cualidades militares que han adquirido, dado que se posicionan con más relevancia en la jerarquía. Aunque hoy en día es más notorio, en la década de los setenta también se resaltaba a quienes habían obtenido esos diez primeros puestos, con lo cual ganaban reconocimiento por su formación como cadete y alférez, lo que les abría, y sigue haciéndolo, la oportunidad de perfilarse como agente dominante en el campo desde sus inicios como oficiales.

En esta ceremonia se glorifica todo el tiempo que pasaron los militares en la EsMic como cadetes y alféreces, los premios y reconocimientos que obtuvieron en forma significativa. En este sentido, se trata de un ritual en el que participan los agentes dominantes del campo militar, como lo es la cúpula militar, y sus dominados (Bourdieu \& Passeron, 1996), que hasta el momento eran cadetes y alféreces, pero que con la graduación ascienden y se posicionan en la jerarquía de los oficiales.

Este acto los legitima frente a los otros campos que tienen injerencia en el campo militar, puesto que al ser mostrados ante los demás, se destacan los medios que han adquirido para acceder a los fines de su campo, al tiempo que son reconocidos y diferenciados de los demás. Este proceso se puede analizar a partir del trabajo de Foucault (1976), quien plantea que "la disciplina 'fabrica' individuos a la vez como objetos y como instrumentos de su ejercicio" (p. 175), pero con la salvedad de que en la EsMic no solo se crean oficiales a través de su educación y régimen disciplinario, sino también mediante los premios y las calificaciones.

Por otra parte, la primera fotografía (figura 1) también deja ver cómo dentro del mismo campo se forman clases, una de las cuales está integrada por los agentes dominantes del campo, quienes se convierten en la élite. Desde que se gradúan como oficiales, del grupo de oficiales superiores y generales sale la cúpula militar, cuyos integrantes tienen más poder en el campo, pero también son menos, pues, por la jerarquía piramidal de las Fuerzas Militares, cuanto más arriba se llega, más selectivo y meritorio es ascender, lo cual implica perfilarse con un estatus entre la élite de los oficiales. Igual ocurre en la EsMiC entre los cadetes, quienes son los dominados y deben adquirir unos habitus, comportamientos que se habitúan en su día a día, en la educación e instruc- 
ción militar. Así pues, reconocen y distinguen los bienes y los capitales simbólicos, que se traducen en un ascenso social, para convertirse en alférez, quienes son dominantes de la Escuela. Asimismo, en este grupo o élite también salen los diez primeros que se convierten en los brigadieres y en el brigadier mayor, rango que solo puede ocupar una persona de todo un curso.

En la década de los setenta la educación militar e instrucción era un programa de ciencias militares. "El programa contemplaba ocho semestres académicos y el complemento de formación militar y entrenamiento práctico, con fundamentos filosóficos, técnicos, culturales de aplicación militar, cuyo propósito era garantizar una educación integral a los nuevos oficiales" (Escuela Superior de Guerra, 1993; citado por Esmic, 2007, p. 559). Además se veían materias complementarias, como Física, Matemáticas, Español, Historia, Geografía, Principios y Valores para quienes terminaban su bachillerato en la Escuela, que eran acompañadas de una instrucción y entrenamiento en guerra irregular. Esta formación era complementada por un régimen que les estipulaba los horarios de clases, instrucción, desayuno, almuerzo y cena, hora de levantarse e ir a dormir, así como los uniformes que debían usar en cada una de estas actividades (Esmic, 2007). Toda esta práctica de educación e instrucción militar se convertía en el mecanismo a través del cual se forman y adquieren los habitus, de tal manera que la misma institución legitima los procesos y prácticas que, más adelante, quienes ya son oficiales reproducen y conservan en el campo, como la jerarquía, los bienes capitales simbólicos y los medios pertenecientes a este.

Estos bienes simbólicos en la formación de la EsMic se evidencian en los uniformes, los distintivos de los grados y las condecoraciones, como las medallas de quienes han tenido un reconocimiento y las ponen en sus uniformes. De igual forma, los capitales simbólicos son los reconocidos ante los otros, por ejemplo el grado o el sable. Además, en el proceso de formación se van incorporando y adquiriendo los habitus, que Bourdieu (1997) explica como la interiorización de prácticas y su normalización en el campo. En el caso de la EsMIC, estas prácticas se incorporan en las aulas mediante las clases, los entrenamientos diarios y la disciplina instaurada del régimen al que se someten día a día los cadetes en su estancia en la Escuela, la cual impone una realidad verídica y aceptada ante el grupo en el que están. 
Por otra parte, el análisis de la segunda fotografía (figura 2) a partir de los conceptos propuestos en la teoría de Bourdieu, Burke y Barthes permite caracterizar el campo militar, en el cual se configuran y entienden los uniformes, los distintivos, las condecoraciones y los grados, capitales propios de este campo que han sido interiorizados por sus integrantes como las actitudes del ser militar, de lo que representa pertenecer a la Esmic. Una de estas actitudes es la apropiación del uniforme, que es exhibido con la elegancia y el porte característico de los agentes más antiguos en el campo, quienes desde su comienzo como cadetes reconocen y legitiman aquello que los define como militares.

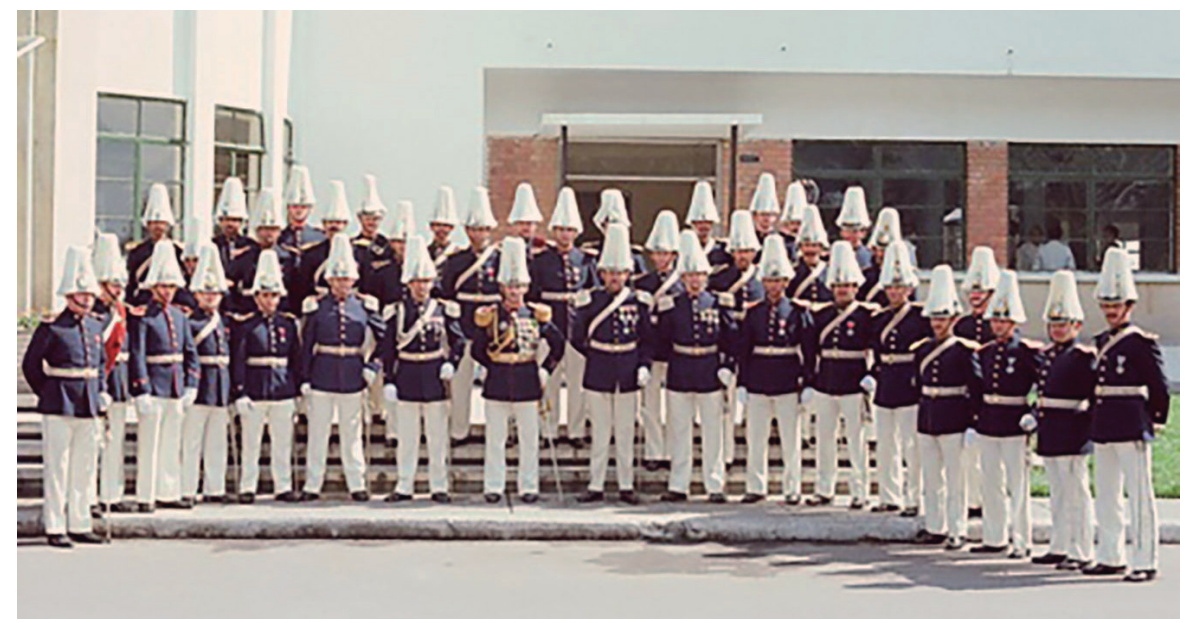

Figura 2. Oficiales de planta de la Esmic (1978).

Fuente: Álvaro Díaz. Archivo fotográfico personal, Bogotá, D. C., Colombia.

En este sentido, la fotografía se convirtió en el testimonio y la evidencia histórica de la representación del ambiente que se vivía en la Escuela. La Esmic, precisamente por ser una institución militar castrense, de alguna forma se apartó del contexto general de Colombia en la década del setenta, pues no tuvo implicación directa con el contexto nacional, aun cuando forma los oficiales que dirigen y comandan a la tropa en las otras regiones del país, y donde estos oficiales se convierten en actores determinantes del contexto social, económico o político del lugar en el que se encuentren. En este sentido, los militares (oficiales, suboficiales, soldados) se convierten en la presencia y control del Estado, esto es, del campo político que tiene injerencia en el campo militar. 
De esta manera se comprende cómo el cadete adquiere un habitus propiamente militar y cómo desde su formación es reconocido por los otros agentes como aquel cuyos pasos deben seguir, al tiempo que son estos a los cuales debe exigirles interiorizar las prácticas que definen el campo militar. Este proceso inicia cuando el cadete asume el uniforme como el primer reconocimiento que lo identifica como agente del campo, símbolo de que pertenece a un grupo; no obstante el grado que pueda tener, con esta prenda forma parte del campo específico de la Esmic. Se trata entonces del primer bien simbólico que representa a los cadetes —además de lo que significa en el campo como un capital simbólico- - y que a medida que pasa el tiempo les permite adquirir otros capitales, como los grados y las condecoraciones. Así, los uniformes refuerzan la idea de que representan al oficial, lo cual es evidente en las dos fotografías. Estos vestigios fueron los indicios que permitieron deducir la existencia de esta interiorización y materialización conceptual que configura el campo militar.

Lo que se ha expuesto hasta acá evidencia el studium, que Barthes (1986) plantea como la selección fotográfica, la motivación e intención que se tiene para escoger las fotos. En este sentido, el archivo fotográfico se depuró, de tal manera que al seleccionar las fotografías se hicieran evidentes los elementos más constantes que reunieran las mismas cualidades del campo militar, pues no se quería caer en la repetición fotográfica, sino usar solamente las necesarias para evidenciar los elementos de análisis que se expusieron en el capítuló ${ }^{4}$.

\section{Conclusiones}

En conclusión, este trabajo investigativo, que constituye un aporte a la sociología histórica, materializó la conceptualización sociológica en una realidad específica: la Esmic. En medio de una década en la que el contexto general del país vivía múltiples situaciones nacionales (sociales, políticas y económicas), la Escuela Militar tuvo una década pasiva, en comparación con

4 Este trabajo se amplía en el análisis y el desarrollo de la tesis que dio como producto este capítulo de investigación. Cabe aclarar que las fotografías estudiadas no tuvieron ninguna edición o tratamiento, en palabras de Barthes, fotogenia, que haya afectado las condiciones de la fotografía o el estudio sociológico e histórico. 
las décadas siguientes, como los ochenta, noventa y principios del siglo XXI. En otras palabras, en la década de los setenta la Escuela Militar no se vio directamente afectada por el contexto general, lo cual permitió que los procesos de formación de los cadetes se desarrollaran de tal forma que se pudiera evidenciar la representación del militar de la época, tal como era para ese momento.

El análisis fotográfico a partir de las categorías aportadas por los estudios de Pierre Bourdieu permitió comprender la representación militar y, específicamente, cómo era el proceso de adquisición e incorporación de los habitus que configuraban el campo militar, así como identificar la jerarquía de las Fuerzas Militares (oficiales, suboficiales y soldados) de la Esmic en el paso de cadetes a alféreces y a oficiales. Con este propósito se analizó el papel que tienen los uniformes usados en la Escuela y el significado de las condecoraciones y de elementos como el sable y la forma de portarlo. En este sentido, el estudio evidencia que el habitus que adquirieron los cadetes y alféreces, como agentes del campo militar, se convirtió en la forma esencial como configuran su representación y toman posición en el campo, así como el referente a partir del cual construyeron las estrategias que necesitan para desenvolverse dentro de este y en los otros campos que tienen injerencia en el campo militar, como el político y el educativo.

Asimismo, este trabajo evidencia cómo todos los agentes del campo militar reconocen y cumplen con su función, a la vez que se autorrepresentan en el papel que les otorga la misma jerarquía del campo, lo cual configura la representación del militar como cadete, alférez y oficial. Es en esta jerarquía en la que cada uno se caracteriza y diferencia, por ejemplo, el cadete en su rol de quien está adquiriendo conocimientos, que entiende unos capitales culturales y simbólicos que necesita para convertirse en alférez y oficial. Así, el análisis de las fotografías permitió caracterizar el campo específico de estudio, aun cuando en este documento solo se presentan 2 de las 25 fotografías seleccionadas para la investigación y tesis, de un archivo de más de 500 fotografías de la Esmic.

Por otra parte, la investigación describe cómo era la jerarquía militar en la Esmic a través de los oficiales, suboficiales y soldados. En este sentido, el estudio de los oficiales en la Esmic da cuenta de una jerarquía piramidal: en un eje se encuentran los oficiales subalternos, superiores y generales, y por otro los oficiales de planta, alféreces y cadetes. De igual forma, se constata que 
los procesos de educación e instrucción militar incorporan bienes, capitales culturales y simbólicos, como los rangos, los distintivos, los uniformes y las condecoraciones, que son interiorizados por los militares hasta convertirlos en habitus. A continuación, la figura 3 describe la síntesis del esquema del campo militar de los oficiales del Ejército Nacional.



Figura 3. Configuración del campo militar en la década de los setenta. Fuente: Díaz (2019).

Finalmente, este estudio permite comprender cuál es y cómo se configuró la representación militar en la Esmic en la década del setenta, para lo cual se materializaron los conceptos sociológicos en el archivo fotográfico. Aun cuando no se analizaron todas las fotografías, estas permitieron extraer la información necesaria para realizar la investigación, además de evidenciar cómo ha sido el proceso de educación e instrucción de los oficiales - la cual puede que siga vigente aún, solo que se diferencia en sus procesos formativos- Si bien este trabajo se planteó específicamente establecer de dónde surge la cúpula militar del Ejército Nacional, quién se convierte en el comandante de las Fuerzas Militares de Colombia y de cada Fuerza, sería interesante desarrollar un estudio similar en las otras escuelas de formación militar de cada Fuerza y de la Policía. 


\section{Referencias}

Barthes, R. (1986). Lo obvio y lo obtuso: Imágenes, gestos, voces. Paidós.

Barthes, R. (1990). La cámara lúcida, notas sobre la fotografía. Paidós.

Becker, H. (1974). Fotografía y sociología. Estudios de Antropología Visual y Comunicaciones, (1), 1-9.

Bourdieu, P. (1997). Sobre la televisión. Anagrama.

Bourdieu, P., \& Passeron, J. (1996). La reproducción: Elementos para una teoría de la enseñanza. Fontamara.

Díaz, A. (2019). Representación militar de la Escuela Militar de Cadetes "General José María Córdova" en la década de los setenta del siglo XX [Tesis de maestría, Escuela Militar de Cadetes "General José María Córdova”].

Díaz, A. (1970-1979). Archivo fotográfico de la Escuela Militar de Cadetes "General José María Córdova”. Bogotá, Colombia.

Escuela Militar de Cadetes "General José María Córdova” [ESMIC]. (2007). Evolución Histórica de la Escuela Militar de Cadetes "General José María Córdova”. Imprenta Nacional de Colombia.

Foucault, M. (1976). Disciplina. En Vigilar y castigar. Siglo XXI. 